\title{
High eukaryotic translation elongation factor 1 alpha 1 expression promotes proliferation and predicts poor prognosis in clear cell renal cell carcinoma
}

\author{
Y. BAO ${ }^{1, *}$, T. L. ZHAO ${ }^{1, *}$, Z. Q. ZHANG ${ }^{1, *}$, X. L. LIANG ${ }^{1, *}$, Z. X. WANG ${ }^{2}$, Y. XIONG ${ }^{1}$, X. LU ${ }^{1, *}$, L. H. WANG ${ }^{1, *}$ \\ ${ }^{1}$ Department of Urology, Changzheng Hospital, Second Military Medical University, Shanghai 200003, China; ${ }^{2}$ Department of Urology, The \\ 458th Hospital of PLA, Guangzhou, 510602, China
}

*Correspondence: luxin_smmu@163.com; wanglinhui@smmu.edu.cn

${ }^{*}$ Contributed equally to this work.

Received February 24, 2019 / Accepted June 19, 2019

\begin{abstract}
Accumulating evidence indicates that eukaryotic translation elongation factor 1 alpha 1 (eEF1A1) is involved in cancer, while the clinical significance and the exact role of eEF1A1 in renal cell carcinoma (RCC) remain obscure. The aim of the present study was to evaluate the clinical significance of eEF1A1 in RCC and to investigate its effective mechanisms in order to identify a potential therapeutic target. The expression levels of eEF1A1 in RCC were explored by immunohistochemistry in tissues from 184 patients. eEF1A1 was knocked down, and cell proliferation and apoptosis were then investigated. The MAPK pathway-related proteins were detected by western blot. Our results revealed that eEF1A1 was highly expressed in RCC tissues and associated with poor prognosis. Knockdown of eEF1A1 attenuated proliferation and promoted the apoptosis of RCC cells. Furthermore, eEF1A1 knockdown decreased the phosphorylation level of AKT and ERK. In conclusion, eEF1A1 may serve as a valuable prognostic biomarker and promising therapeutic target of RCC.
\end{abstract}

Key words: clear cell renal cell carcinoma, eEF1A1, biomarker, AKT, ERK

Renal cell carcinoma (RCC) accounts for approximately $4 \%$ of all adult malignancies and represents the most lethal urologic cancer, with an estimated 61,560 new cases and 14,080 deaths in the United States in 2015 [1]. Metastatic RCC, characterized by a high resistance to radiotherapy and chemotherapy, has a poor prognosis with a 5-year survival rate of $0-20 \%[2,3]$. Therefore, developing novel therapeutic approaches based on a better understanding of the molecular mechanism of RCC pathogenesis is urgent.

A protein called eukaryotic translation elongation factor 1 alpha (eEF1A) is involved in the final stages of protein production. To make a protein, a messenger RNA molecule binds to a ribosome and then translates the messenger RNA sequence into a protein by joining together individual building blocks called amino acids in the correct order, and in this process, eEF1A helps to select the amino acids that match the sequence of the messenger RNA template [4]. eEF1A in mammalian cells has two isoforms, eEF1A1 and eEF1A2, which are encoded by genes that share $92 \%$ sequence identity (EEF1A1, NM_001402 and EEF1A2, NM_001958) and share the same canonical function [5]. The majority of cells express the eEF1A1 isoform, and only adult neuronal and muscle cells express eEF1A2 $[6,7]$. Therefore, the function of eEF1A1 has been the focus of a research. eEF1A1 is a 50 $\mathrm{kDa}$ GTPase that couples the hydrolysis of GTP to GDP with the delivery of amino acyl tRNAs to the ribosome during protein translation $[8,9]$. Recently, it has been suggested that eEF1A1 is not only a translation factor but also a pleiotropic protein that is highly expressed in human tumors [10-13]. eEF1A1 modulates the cytoskeleton, exhibits chaperone-like activity and controls cell proliferation and cell death $[14,15]$. However, the role of eEF1A1 in RCC has not been explored.

In the present study, we first used a tissue microarray including RCC tissues and adjacent tissues from 184 patients to examine the protein level of eEF1A1. We found that eEF1A1 was highly expressed in RCC tissues and could serve as a prognostic biomarker. Furthermore, eEF1A1 knockdown could inhibit proliferation and promote the apoptosis of cancer cells by regulating AKT/ERK phosphorylation levels.

\section{Patients and methods}

Patients and specimens. A total of 184 cases of RCC tissues were collected at the Changhai Hospital, Shanghai, China from January 2007 to March 2009. Tissue samples for prognostic purposes were obtained with the consent of each patient, and 
each specimen was analyzed by routine pathological analysis. This study was approved by the Institutional Review Board of the Changhai Hospital, Second Military Medical University. All the patients underwent radical nephrectomy, and the pathology results were all clear cell RCC. None of the patients had synchronous cancers, previous urologic diseases or had undergone abdominal surgery, chemotherapy or radiotherapy prior to specimen collection. A tissue microarray (TMA) was constructed from these specimens.

Immunohistochemistry. Immunohistochemistry assays were performed according to the manufacturer's instructions. The primary antibody was anti-eEF1A1 (Santa Cruz, sc-21758, 1:50). High-resolution images were captured with an Aperio Scan Scope AT Turbo (Aperio, USA) equipped with Aperio ImageScope software (Aperio, USA). The assessment of the staining was based on the staining intensity and the percentage of positively stained cells using Image-Pro Plus 6.0 software (Media Cybernetics, Inc., USA). The median signal of eEF1A1-positive staining was defined as the cut-off value.

Cell culture. Human RCC cells (A498, Caki-2) were purchased from the Chinese Academy of Sciences (Shanghai, China). A498 cells were grown in MEM (10-010-CV, Corning, United States) supplemented with $10 \%$ fetal bovine serum (FBS; 16000044, Gibco, United States). Caki-2 cells were cultured in RPMI 1640 (10-040-CV, Corning, United States) containing $10 \%$ FBS. The cells were maintained at $37^{\circ} \mathrm{C}$ in a humidified atmosphere of $5 \% \mathrm{CO}_{2}$.

Lentiviral vectors and infection. The eEF1A1 RNA interference lentivirus vector was constructed at Hanbio Biotechnology (Shanghai, China). The shRNA sequencing was as follows: sh-eEF1A1\#1 5'-GGGTCTTGGATAAACTGAAAG-3'; sh-eEF1A1\#2 5'-GCTGCTGGTGTTGGTGAATTT-3'; and sh-NC CTCCGAACGTGTCACGT. The Caki-2 and A498 cell lines were infected with lentiviruses encoding sh-NC, sh-eEF1A1\#1 or sh-eEF1A1\#2 for $24 \mathrm{~h}$ and subsequently placed in fresh medium, while the non-infected cells were used as a blank control. The cells were cultured for the next $48 \mathrm{~h}$ and then puromycin was added to the culture medium (Invivogen, $2 \mu \mathrm{g} / \mathrm{ml}$ ). Stable puromycin-resistant cell lines were obtained after three generations and used for the following experiments.

RNA extraction, cDNA synthesis and quantitative PCR (qPCR). RNA was extracted from cells using TRIzol reagent (15596018, Life Technologies, United States) according to the manufacturer's instructions and reverse transcribed to cDNA using PrimeScript ${ }^{\text {tix }}$ RT Master Mix and a reverse transcription reagent kit (RR036A, Takara, Japan). cDNA was used as the template for quantitative PCR, which was performed using the LightCycler ${ }^{\bullet} 480$ Detection System (Roche, Switzerland). The primers used for PCR were obtained from Sangon Biotech (Shanghai, China). GAPDH mRNA was employed as an endogenous control for mRNA. The primer sequences were as follows: eEF1A1, forward (5'-3') GATTCCACTGAGCCACCCTA, and reverse (5'-3') TGTCACCATTCCAACCAGAA; and GAPDH, forward (5'-3') AGAAGGCT-
GGGGCTCATTTG, and reverse (5'-3') AGGGGCCATCCACAGTCTTC. The PCR conditions were as follows: initial denaturation at $94^{\circ} \mathrm{C}$ for $2 \mathrm{~min}$, followed by 40 cycles of denaturation at $94^{\circ} \mathrm{C}$ for $30 \mathrm{~s}$, annealing at $60^{\circ} \mathrm{C}$ for $20 \mathrm{~s}$, and extension at $72^{\circ} \mathrm{C}$ for $20 \mathrm{~s}$, and then a final extension step at $72^{\circ} \mathrm{C}$ for $5 \mathrm{~min}$. GAPDH was amplified as an internal reference gene, and the $2^{-\triangle \Delta C T}$ method was used to quantify the amplified fragments.

Western blot assay. The total soluble proteins extracted were resolved on $10 \%$ SDS-polyacrylamide gels and transferred electrophoretically to PVDF membranes. The blots were blocked with 5\% skim milk and then incubated with the following primary antibodies: anti-eEF1A1 (Santa Cruz, sc-21758, 1:50), anti- $\beta$-actin (Sangon Biotech, D1906060100), anti-AKT (Cell Signaling Technology, 9272), antip-AKT (Cell Signaling Technology, 4060), anti-ERK (Cell Signaling Technology, 4695), and anti-p-ERK (Cell Signaling Technology, 4370). The blots were then incubated with an anti-rabbit or anti-mouse secondary antibody (Santa Cruz Biotechnology, Santa Cruz, CA) and visualized by enhanced chemiluminescence.

In vitro proliferation assay. Cell proliferation was determined by Cell Counting Kit-8. A498 and Caki- 2 cells were seeded in 96-well plates at a density of 1000 cells in $100 \mu \mathrm{l}$ of culture medium per well and incubated at $37^{\circ} \mathrm{C}$ in an atmosphere of $5 \% \mathrm{CO}_{2}$. At 24, 48, 72, 96, 120 and $144 \mathrm{~h}, 10 \mu \mathrm{l}$ of CCK-8 reagent (Dojindo Molecular Technologies, Japan) was added to each well and incubated for $1.5 \mathrm{~h}$. Absorbance was measured using a microplate reader (Varioskan Flash, Thermo Scientific, United States) at a wavelength of $450 \mathrm{~nm}$. Three parallel wells were set up for each experiment and repeated three times.

Apoptotic analysis with Annexin V staining. Cells were seeded in a 6-well plate, collected, washed twice with ice-cold phosphate-buffered saline (PBS), and resuspended in $1 \mathrm{ml}$ of $1 \times$ binding buffer. Then, $100 \mu$ l of cell suspension was labelled with $5 \mu$ of fluorescein isothiocyanate (FITC)-conjugated Annexin $\mathrm{V}$ and $5 \mu \mathrm{l}$ of propidium iodine according to the manufacturer's instructions (556547, BD Pharmingen ${ }^{\mathrm{m} w}$, United States). After incubation at room temperature (RT; $25^{\circ} \mathrm{C}$ ) in the dark for $15 \mathrm{~min}$, the samples were supplemented with $400 \mu$ l of $1 \times$ binding buffer and then immediately analyzed on a flow cytometer (MACSQuant, Miltenyi Biotec, Germany) within $1 \mathrm{~h}$.

Tumor xenograft assay. Male BALB/c nude mice (4 weeks old) were purchased from the Shanghai Experimental Animal Center of the Chinese Academy of Sciences (Shanghai, China). The mice were housed in pathogen-free conditions, and all procedures were performed in accordance with the Second Military Medical University animal welfare guidelines. RCC cells (approximately $5 \times 10^{6}$ cells per site) were injected subcutaneously into the lateral area of the proximal thighs of the mice. Tumor volume was monitored every 6 days from the day after inoculation by measuring the tumor length (L) and width (W) with a sliding caliper. 
TUNEL assay. The TUNEL assay kit was purchased from Roche, and the assay was performed according to the manufacturer's instructions. Briefly, sections were incubated in xylene and dehydrated in pure ethanol. The solution was covered with a protease hydrazine solution and incubated at $37^{\circ} \mathrm{C}$ for $25 \mathrm{~min}$. Any excess liquid was then discarded. The permeabilization working solution was added to cover the target tissue and then incubated for $20 \mathrm{~min}$ at RT. Reagent 1 (TdT) and reagent 2 (dUTP) (both from the TUNEL assay kit) were mixed at a ratio of 1:9. The mixture was added to the target tissue, placed in a desiccant box and incubated for $2 \mathrm{~h}$ at $37^{\circ} \mathrm{C}$. The slides were washed three times with PBS, and then $3 \%$ bovine serum albumin (BSA) was added to cover the labelled tissue to block non-specific binding for $30 \mathrm{~min}$. The slides were then incubated with the DAPI solution for 10 min at RT, maintained in the dark, and detected by fluorescence microscopy. DAPI emits blue light at a UV excitation wavelength of 330-380 $\mathrm{nm}$ and has an emission wavelength of $420 \mathrm{~nm}$. FITC emits green light at 465-495 $\mathrm{nm}$ and has an emission wavelength of 515-555 $\mathrm{nm}$.
Statistical analysis. All statistical analyses were carried out using the SPSS software statistical package (version 22.0; SPSS, Inc., Chicago, IL, USA). The relationships between the differential expression of eEF1A1 and clinicopathological characteristics and prognosis were evaluated by the $\chi^{2}$ test and Kaplan-Meier survival analysis. Student's t-test was used to evaluate the differences between two groups. A p-value $<0.05$ was considered to indicate a statistically significant result.

\section{Results}

eEF1A1 is highly expressed in RCC tissues compared with adjacent tumor tissues, and high eEF1A1 levels predict poor prognosis in RCC patients. eEF1A1 protein levels were examined in a cohort from the Changhai Hospital including $184 \mathrm{ccRCC}$ patients. We found that eEF1A1 levels were higher in tumor tissues than in adjacent normal tissues (Figures 1A and 1B). The relationship between the clinicopathological features and the relative expression of eEF1A1
A

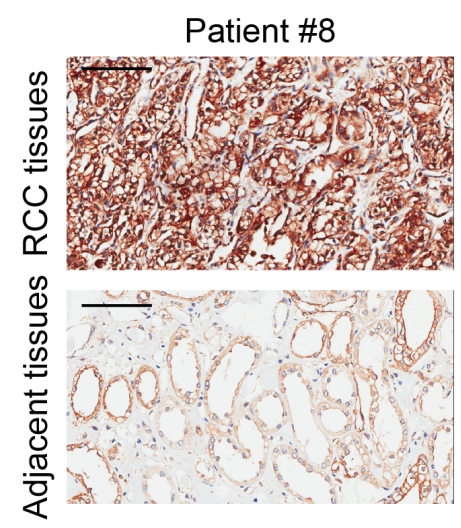

B

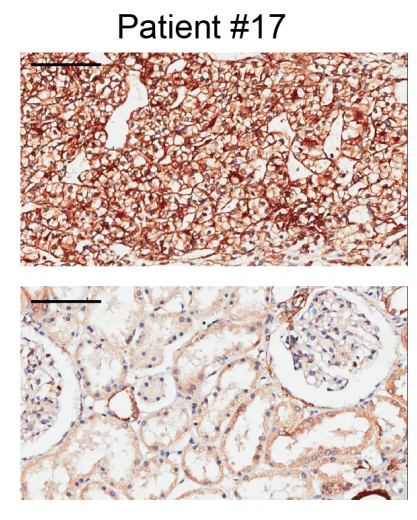

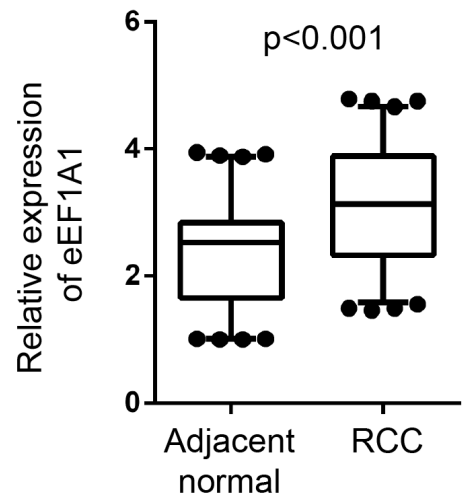

C
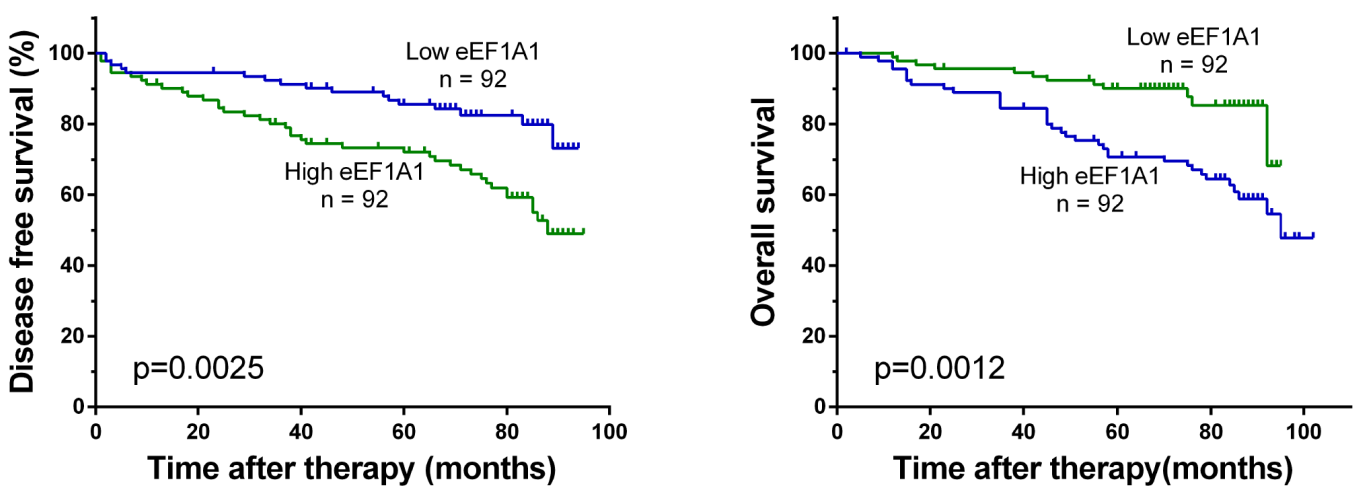

Figure 1. eEF1A1 is highly expressed in RCC tissues compared with adjacent tumor tissues, and high eEF1A1 levels predict poor prognosis in RCC patients. A) Immunohistochemical analysis of eEF1A1 protein levels in RCC tissues. Representative immunohistochemistry images are shown. The scale bar represents $100 \mu \mathrm{m}$. B) eEF1A1 expression in human ccRCC tissues and adjacent tissues determined by immunohistochemistry analysis in a cohort including 184 patients. The horizontal lines in the box plots represent the median, the boxes represent the interquartile range, and the whiskers represent the 2.5 th and 97.5 th percentiles. C) Kaplan-Meier analysis of DFS (left, $p=0.0025$, log-rank test) or OS (right, p=0.0073, log-rank test) of ccRCC patients in the low eEF1A1 group $(n=92)$ and high eEF1A1 group $(n=92)$ from the cohort including 184 patients. 
in RCC tissues is summarized in Table 1. The results showed that high eEF1A1 expression was associated with aggressive clinical features, such as higher Fuhrman grade and higher ratio of metastasis. Survival analysis showed that patients with higher eEF1A1 levels exhibited shorter diseasefree survival (DFS) and overall survival (OS) (Figure 1C). Multivariate analysis identified high eEF1A1 levels in RCC tissues as an independent prognostic factor for RCC patients (Table 2 and Table 3 ). Taken together, these results suggested an oncogenic role of eEF1A1 and predicted poor prognosis in RCC patients.

eEF1A1 knockdown attenuates proliferation and promotes the apoptosis of RCC cells in vitro and in vivo. A498 and Caki-2 cells were infected by lentiviruses that contained two independent short hairpins (shRNAeEF1A1\#1 and shRNA-eEF1A1\#2) or an empty vector (sh-NC). The levels of eEF1A1 expression in the A498 and Caki-2 cells were assessed by qPCR and western blot. Compared with those in the sh-NC cells, the mRNA and protein expression levels of eEF1A1 in the shRNAeEF1A1\#1 and shRNA-eEF1A1\#2 cells were decreased significantly (Figures 2A, 2B). Then, cell counting kit-8 assays were employed for analysis and we found that the eEF1A1 knockdown suppressed the proliferation of RCC cells compared to that of the empty vector groups (Figure 2C). Flow cytometry analysis was used to detect the number of apoptotic cells, and the results showed that the suppression of eEF1A1 enhanced the ratio of early and late apoptotic cells (Figure 2D).

To further explore the role of eEF1A1 in RCC growth in vivo, Caki-2 cells transfected with sh-eEF1A1\#1 or sh-NC cells were injected subcutaneously into nude mice. As shown in Figure $3 \mathrm{~A}$ and $3 \mathrm{~B}$, the tumor volumes were reduced in the eEF1A1 shRNA group compared to those of the negative control group. The TUNEL assay demonstrated that the number of apoptotic cells was increased in tumors from the eEF1A1 shRNA group (Figure 3C). Taken together, these results revealed that eEF1A1 knockdown attenuates proliferation and promotes the apoptosis of RCC cells in vitro and in vivo.

eEF1A1 knockdown decreases the phosphorylation level of AKT and ERK. eEF1A has been reported to possibly bind to AKT and ERK and affect their phosphorylation $[16,17]$. Pecorari et al. confirmed that one of the pAkt interacting proteins is the elongation factor EF1a that contains a putative AKT phosphorylation site, and the downregulation of EF1a expression by siRNAs led to a markedly decreased expression of pAkt [17]. Sanges et al. identified that eEF1A is closely related to ERK [16]. eEF1A has two isoforms, eEF1A1 and eEF1A2, which are encoded by genes that share $92 \%$ sequence identity and share the same canonical function. A majority of cells express the eEF1A1 isoform. Therefore, we hypothesized that EEF1A1 will affect the phosphorylation of AKT and ERK. We detected the phosphorylation levels of AKT and
ERK after eEF1A1 knockdown and observed a significant decrease in their phosphorylation levels (Figure 4). These results indicate that eEF1A1 regulates the proliferation and apoptosis of RCC cells by regulating the phosphorylation levels of AKT and ERK.

Table 1. Correlation between eEF1A1 protein level and clinical characteristic in RCC patients.

\begin{tabular}{|c|c|c|c|c|}
\hline \multirow[b]{2}{*}{ Variables } & \multirow{2}{*}{$\begin{array}{c}\text { Total } \\
(\mathrm{n}=184)\end{array}$} & \multicolumn{2}{|c|}{ eEF1A1 } & \multirow[b]{2}{*}{ p-value } \\
\hline & & $\begin{array}{l}\text { Low expression } \\
\qquad(\mathrm{n}=92)\end{array}$ & $\begin{array}{l}\text { High expression } \\
\qquad(\mathrm{n}=92)\end{array}$ & \\
\hline Gender & & & & 0.789 \\
\hline Male & 115 & 59 & 56 & \\
\hline Female & 69 & 34 & 35 & \\
\hline Age & & & & 0.522 \\
\hline$<60 y$ & 71 & 38 & 33 & \\
\hline$\geq 60 y$ & 113 & 55 & 58 & \\
\hline Tumor size & & & & 0.955 \\
\hline$\leq 7 \mathrm{~cm}$ & 125 & 63 & 62 & \\
\hline$>7 \mathrm{~cm}$ & 59 & 30 & 29 & \\
\hline Fuhrman Grade & & & & 0.008 \\
\hline I-II & 128 & 73 & 55 & \\
\hline III-IV & 56 & 20 & 36 & \\
\hline Tumor thrombus & & & & 0.081 \\
\hline No & 165 & 87 & 78 & \\
\hline Yes & 19 & 6 & 13 & \\
\hline Metastasis & & & & $<0.001$ \\
\hline No & 158 & 90 & 68 & \\
\hline Yes & 26 & 3 & 23 & \\
\hline
\end{tabular}

Table 2. Univariate and multivariate analyses of factors associated with progress free survival in the cohort.

\begin{tabular}{lcccc}
\hline \multirow{2}{*}{ Variable } & \multirow{2}{*}{ Univariate } & \multicolumn{3}{c}{ Multivariate } \\
\cline { 3 - 5 } & & Hazard Ration & $\mathbf{9 5 \%}$ CI & p-value \\
\hline $\begin{array}{c}\text { eEF1A1 expression } \\
\text { High vs Low }\end{array}$ & $<0.001$ & 2.536 & $1.311-4.908$ & 0.0057 \\
$\begin{array}{c}\text { Fuhrman grade } \\
\text { III-IV vs I-II }\end{array}$ & 0.015 & 1.122 & $0.610-2.063$ & 0.7114 \\
$\begin{array}{c}\text { Tumor thrombus } \\
\text { Yes vs No }\end{array}$ & 0.001 & 2.164 & $1.042-4.497$ & 0.0385 \\
$\begin{array}{c}\text { Distant metastasis } \\
\quad \text { Yes vs No }\end{array}$ & $<0.001$ & 5.926 & $3.239-10.842$ & $<0.001$ \\
\hline
\end{tabular}

Table 3. Univariate and multivariate analyses of factors associated with overall survival in the cohort.

\begin{tabular}{lcccc}
\hline \multirow{2}{*}{ Variable } & \multirow{2}{*}{ Univariate } & \multicolumn{3}{c}{ Multivariate } \\
\cline { 3 - 5 } & & Hazard Ration & $\mathbf{9 5 \%}$ CI & p-value \\
\hline $\begin{array}{l}\text { eEF1A1 expression } \\
\quad \text { High vs Low }\end{array}$ & $<0.001$ & 3.856 & $1.518-9.795$ & 0.0045 \\
$\begin{array}{c}\text { Tumor thrombus } \\
\quad \text { Yes vs No }\end{array}$ & 0.0012 & 6.166 & $2.050-18.545$ & 0.0012 \\
$\begin{array}{c}\text { Distant metastasis } \\
\quad \text { Yes vs No }\end{array}$ & $<0.001$ & 13.869 & $4.675-9.795$ & $<0.001$ \\
\hline
\end{tabular}


A

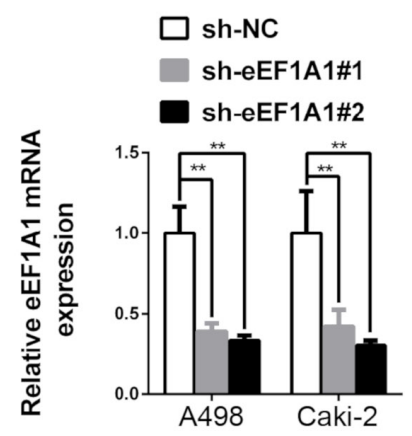

B

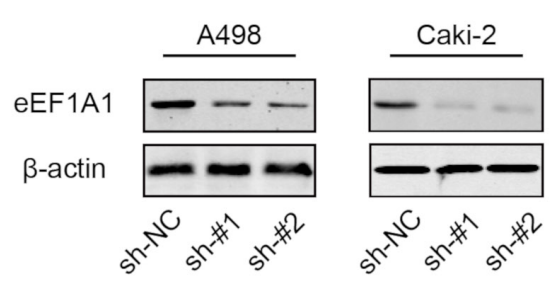

C
A498

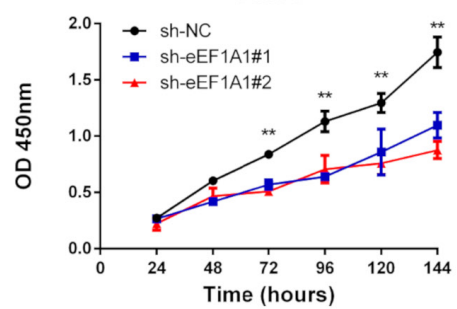

Caki-2

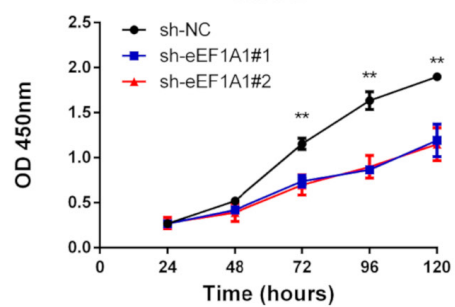

D

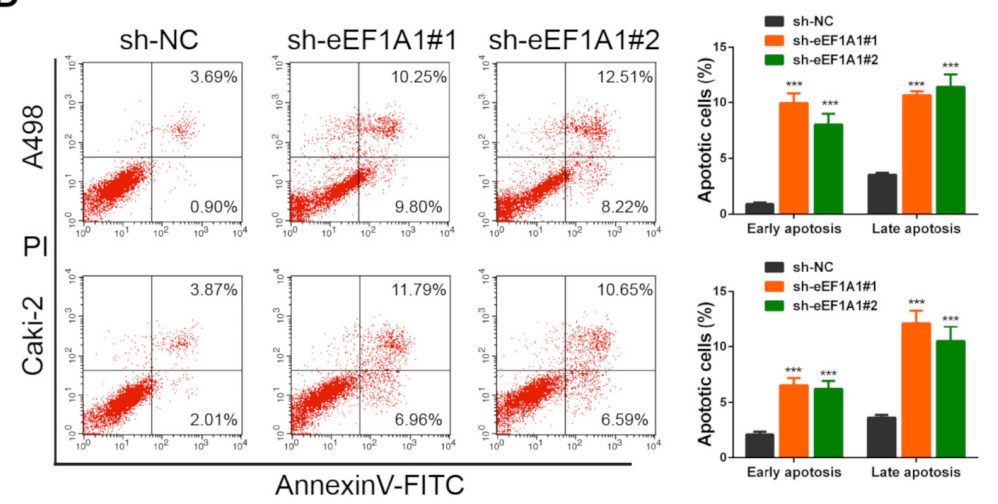

Figure 2. eEF1A1 knockdown attenuates proliferation and promotes the apoptosis of RCC cells in vitro. A) qRT-PCR analysis of eEF1A1 mRNA levels in eEF1A1-knockdown and control A498 and Caki-2 cells $(n=3)$. B) Western blot analysis of eEF1A1 in A498 and Caki-2 cells transfected with sheEF1A1\#1, sh-eEF1A1\#2 or control sh-NC lentiviruses $(n=3)$. $\beta$-Actin was used as a loading control. C) CCK-8 assay of eEF1A1 knockdown and control A498 and Caki-2 cells at the indicated times $(n=3)$. D) Flow cytometry analysis of apoptotic cells in eEF1A1 knockdown and control A498 and Caki-2 cells (left) and the percentage of cells at the different apoptotic phases (right).
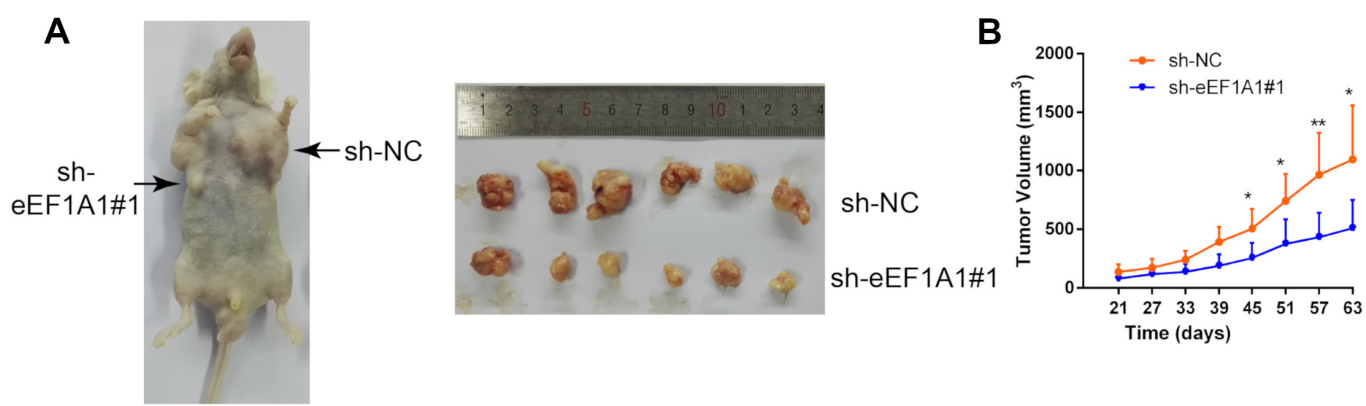

C

sh-NC

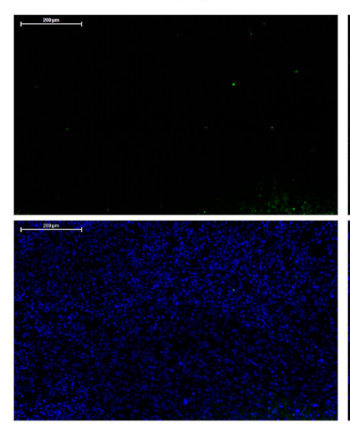

sh-eEF1A1\#1

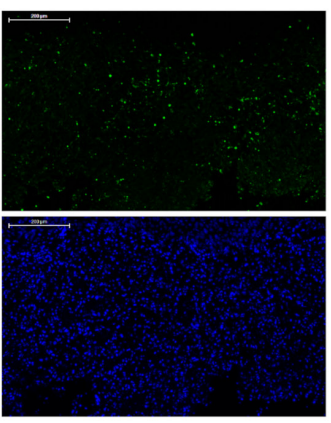

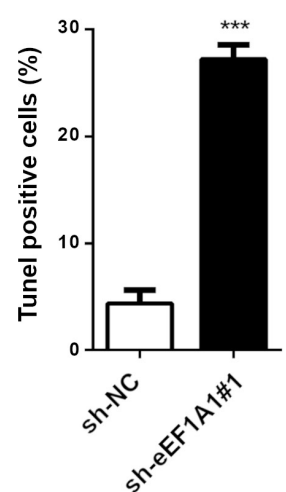

Figure 3. eEF1A1 knockdown suppresses tumor growth in vivo. A) Representative nude mice showing the morphology of the tumors derived from eEF1A1 knockdown and control Caki-2 cells (left). The tumors were dissected and photographed (right). B) The growth curve of the tumors derived from eEF1A1 knockdown and control Caki-2 cells. C) TUNEL assay analysis of cell apoptosis in eEF1A1 knockdown and control Caki-2 cell tumors (left). The percentage of apoptotic cells per view is shown (right). Scale bar $=200 \mu \mathrm{m}$. 

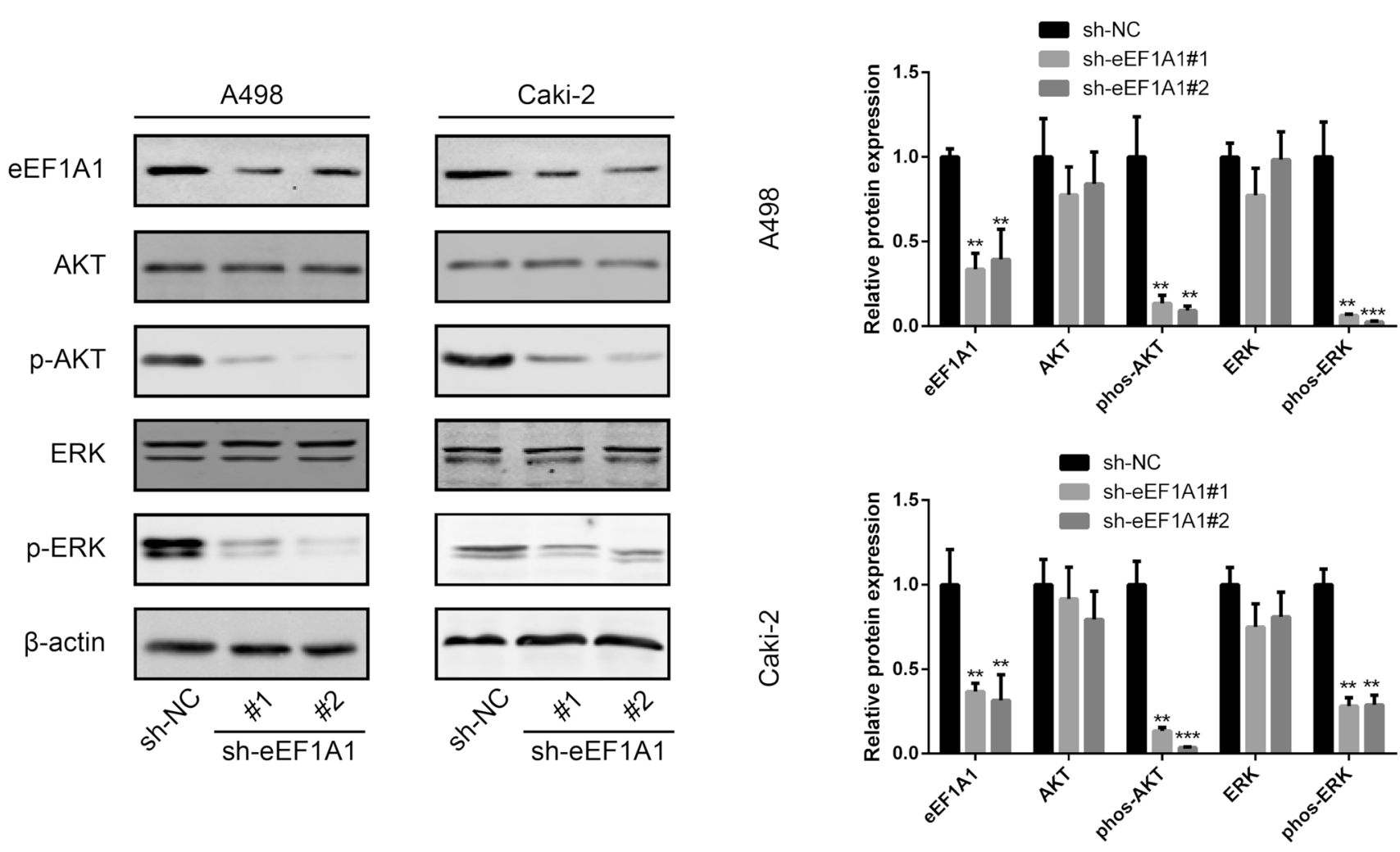

Figure 4. eEF1A1 knockdown decreases the phosphorylation level of AKT and ERK. Western blot analysis of the indicated proteins in A498 and Caki-2 cells transfected with sh-eEF1A1\#1, sh-eEF1A1\#2 or control sh-NC lentiviruses $(\mathrm{n}=3)$. $\beta$-Actin was used as a loading control. The relative expression levels of the proteins were obtained by measuring the grey value by Image-Pro Plus $(n=3)$.

\section{Discussion}

Translation is the central event leading to protein synthesis, and translation factors are key actors involved in the translation process [18]. Recently, it has been suggested that eEF1A1 is not only a translation factor but also a pleiotropic protein that is highly expressed in human tumors, such as hepatocellular carcinoma and gastric cancer [19-24]. However, the role of eEF1A1 in RCC has not been reported.

In the present study, the expression of eEF1A1 in RCC specimens was investigated for the first time, and the results showed that a high expression of eEF1A1 was more likely to occur in RCC tissues and indicated a poor prognosis. Then, we used lentiviral-mediated shRNA silencing of the eEF1A1 gene and successfully obtained stably transfected A498 and Caki-2 cells. We observed that eEF1A1 knockdown significantly inhibited proliferation and promoted apoptosis.

AKT and ERK are kinase pathways that have attracted much attention because of their central role in regulating cell proliferation, survival, motility and angiogenesis [25]. eEF1A1 has been reported to interact with phosphor-AKT in breast cancer cells and regulates their proliferation and survival [17]. Here, we showed that eEF1A1 knockdown inhibited the phosphorylation of AKT and ERK, providing new evidence for further study, although more experiments are needed. Based on comprehensive literature reports and our research results, we believe that eEF1A1 may be a powerful chaperone protein and can be further studied using proteomics methods.

In summary, our present study shows that eEF1A1 was upregulated in RCC tissues and associated with a poor prognosis. The silencing of eEF1A1 using RNA interference could decrease the phosphorylation level of AKT and ERK, leading to proliferation inhibition and an increase in apoptosis. Based on these results, eEF1A1 may serve as a valuable prognostic biomarker and promising therapeutic target of RCC.

\section{References}

[1] SIEGEL RL, MILLER KD, JEMAL A. Cancer statistics, 2015. CA Cancer J Clin 2015; 65: 5-29. https://doi.org/10.3322/ caac. 21254

[2] CAPITANIO U, MONTORSI F. Renal cancer. Lancet 2016; 387: 894-906. https://doi.org/10.1016/S01406736(15)00046-X 
[3] GONG J, MAIA MC, DIZMAN N, GOVINDARAJAN A, PAL SK. Metastasis in renal cell carcinoma: Biology and implications for therapy. Asian J Urol 2016; 3: 286-292. https:// doi.org/10.1016/j.ajur.2016.08.006

[4] JAKOBSSON ME, MALECKI J, NILGES BS, MOEN A, LEIDEL SA et al. Methylation of human eukaryotic elongation factor alpha (eEF1A) by a member of a novel protein lysine methyltransferase family modulates mRNA translation. Nucleic Acids Res 2017; 45: 8239-8254. https://doi. org/10.1093/nar/gkx432

[5] LUND A, KNUDSEN SM, VISSING H, CLARK B, TOMMERUP N. Assignment of human elongation factor 1 alpha genes: EEF1A maps to chromosome 6q14 and EEF1A2 to 20q13.3. Genomics 1996; 36: 359-361. https://doi. org/10.1006/geno.1996.0475

[6] HERSHEY JW. Translational control in mammalian cells. Annu Rev Biochem 1991; 60: 717-755. https://doi. org/10.1146/annurev.bi.60.070191.003441

[7] PANWAR D, RAWAL L, ALI S. Molecular docking uncovers TSPY binds more efficiently with eEF1A2 compared to eEF1A1. J Biomol Struct Dyn 2015; 33: 1412-1423. https:// doi.org/10.1080/07391102.2014.952664

[8] MIGLIACCIO N, RUGGIERO I, MARTUCCI NM, SANGES C, ARBUCCI $S$ et al. New insights on the interaction between the isoforms 1 and 2 of human translation elongation factor 1A. Biochimie 2015; 118: 1-7. https://doi. org/10.1016/j.biochi.2015.07.021

[9] MALECKI J, AILENI VK, HO AYY, SCHWARZ J, MOEN A et al. The novel lysine specific methyltransferase METTL21B affects mRNA translation through inducible and dynamic methylation of Lys-165 in human eukaryotic elongation factor 1 alpha (eEF1A). Nucleic Acids Res 2017; 45: 4370-4389. https://doi.org/10.1093/nar/gkx002

[10] SCAGGIANTE B, FARRA R, DAPAS B, BAJ G, POZZATO $\mathrm{G}$ et al. Aptamer targeting of the elongation factor $1 \mathrm{~A}$ impairs hepatocarcinoma cells viability and potentiates bortezomib and idarubicin effects. Int J Pharm 2016; 506: 268279. https://doi.org/10.1016/j.ijpharm.2016.04.031

[11] FAN Z, CUI X, WEI D, LIU W, LI B et al. eEF1A1 binds and enriches protoporphyrin IX in cancer cells in 5-aminolevulinic acid based photodynamic therapy. Sci Rep 2016; 6: 25353. https://doi.org/10.1038/srep25353

[12] CARELLI JD, SETHOFER SG, SMITH GA, MILLER HR, SIMARD JL et al. Ternatin and improved synthetic variants kill cancer cells by targeting the elongation factor-1A ternary complex. Elife 2015; 4. https://doi.org/10.7554/eLife.10222

[13] BURGLOVA K, RYLOVA G, MARKOS A, PRICHYSTALOVA $\mathrm{H}$, SOURAL $\mathrm{M}$ et al. Identification of eEF1A1 Gamendazole-Binding Site for Binding of 3-Hydroxy-4 $(1 \mathrm{H})$ Quinolinones as Novel Ligands with Anticancer Activity. J Med Chem 2018; 61: 3027-3036. https://doi.org/10.1021/ acs.jmedchem. 8 b00078
[14] GARNER AL, JANDA KD. Protein-protein interactions and cancer:targeting the central dogma.CurrTop Med Chem 2011; 11: 258-280. https://doi.org/10.2174/156802611794072614

[15] CLEMENS MJ. Targets and mechanisms for the regulation of translation in malignant transformation. Oncogene 2004; 23: 3180-3188. https://doi.org/10.1038/sj.onc.1207544

[16] SANGES C, SCHEUERMANN C, ZAHEDI RP, SICKMANN A, LAMBERTI A et al. Raf kinases mediate the phosphorylation of eukaryotic translation elongation factor $1 \mathrm{~A}$ and regulate its stability in eukaryotic cells. Cell Death Dis 2012; 3: e276. https://doi.org/10.1038/cddis.2012.16

[17] PECORARI L, MARIN O, SILVESTRI C, CANDINI O, ROSSI E et al. Elongation Factor 1 alpha interacts with phospho-Akt in breast cancer cells and regulates their proliferation, survival and motility. Mol Cancer 2009; 8: 58. https:// doi.org/10.1186/1476-4598-8-58

[18] HAMEY JJ, WILKINS MR. Methylation of Elongation Factor 1A: Where, Who, and Why? Trends Biochem Sci 2018; 43: 211-223. https://doi.org/10.1016/j.tibs.2018.01.004

[19] CHEN SL, LU SX, LIU LL, WANG CH, YANG X et al. eEF1A1 Overexpression Enhances Tumor Progression and Indicates Poor Prognosis in Hepatocellular Carcinoma. Transl Oncol 2018; 11: 125-131. https://doi.org/10.1016/j. tranon.2017.11.001

[20] LI X, LI J, LI F. P21 activated kinase 4 binds translation elongation factor eEF1A1 to promote gastric cancer cell migration and invasion. Oncol Rep 2017; 37: 2857-2864. https:// doi.org/10.3892/or.2017.5543

[21] HUANG J, ZHENG C, SHAO J, CHEN L, LIU X et al. Overexpression of eEF1A1 regulates G1-phase progression to promote HCC proliferation through the STAT1-cyclin D1 pathway. Biochem Biophys Res Commun 2017; 494: 542549. https://doi.org/10.1016/j.bbrc.2017.10.116

[22] RAZAFINJATOVO C, BIHR S, MISCHO A, VOGL U, SCHMIDINGER $\mathrm{M}$ et al. Characterization of VHL missense mutations in sporadic clear cell renal cell carcinoma: hotspots, affected binding domains, functional impact on pVHL and therapeutic relevance. BMC Cancer 2016; 16: 638. https://doi.org/10.1186/s12885-016-2688-0

[23] LIU X, CHEN L, GE J, YAN C, HUANG Z et al. The ubiquitin-like protein FAT10 stabilizes eEF1A1 expression to promote tumor proliferation in a complex manner. Cancer Res 2016; 76: 4897-4907. https://doi.org/10.1158/0008-5472. CAN-15-3118

[24] FAN Z, CUI X, WEI D, LIU W, LI B et al. eEF1A1 binds and enriches protoporphyrin IX in cancer cells in 5-aminolevulinic acid based photodynamic therapy. Sci Rep 2016; 6: 25353. https://doi.org/10.1038/srep25353

[25] MIGLIACCIO N, SANGES C, RUGGIERO I, MARTUCCI NM, RIPPA E et al. Raf kinases in signal transduction and interaction with translation machinery. Biomol Concepts 2013; 4: 391-399. https://doi.org/10.1515/bmc-2013-0003 